\title{
Pollen Typhae total flavone improves insulin-induced glucose uptake through the $\beta$-arrestin-2-mediated signaling in C2C12 myotubes
}

\author{
XIAO-TAO FENG ${ }^{1,2}$, TIAN-ZHAN WANG ${ }^{1}$, YI CHEN $^{1}$, JI-BO LIU $^{3}$, \\ YI LIU ${ }^{1}$ and WEN-JIAN WANG ${ }^{1,4}$
}

\author{
${ }^{1}$ Institute of Chinese Integrative Medicine, Huashan Hospital, Fudan University, Shanghai; \\ ${ }^{2}$ Guangxi Scientific Experimental Center of Traditional Chinese Medicine, Guangxi University of Chinese Medicine, \\ Nanning; ${ }^{3}$ Department of Endocrinology, Longhua Hospital, Shanghai University of Chinese Medicine, Shanghai; \\ ${ }^{4}$ Institute of Integrative Clinical Medicine, Shanghai Academy of Traditional Chinese Medicine, Yueyang \\ Integrative Medicine Hospital, Shanghai University of Chinese Medicine, Shanghai, P.R. China
}

Received March 13, 2012; Accepted May 11, 2012

DOI: $10.3892 /$ ijmm.2012.1061

\begin{abstract}
Defects in insulin-stimulated glucose uptake in skeletal muscle result from the dysfunction of insulin signaling including the phosphatidylinositol-3 kinase (PI3K) pathway and a novel $\beta$-arrestin-2-mediated signaling, which leads to insulin resistance (IR). Pollen Typhae, a Chinese herb, has been used for thousands of years in traditional Chinese medicine, and has the potential to inhibit the development of IR. We have previously reported that Pollen Typhae total flavone (PTF), the extract from Pollen Typhae, ameliorates high-glucose- and high-insulin-induced impairment of glucose uptake in 3T3-L1 adipocytes, but the mechanisms remain unclear. The objective of this study was to investigate the effects of PTF on glucose uptake, and to explore the underlying mechanisms in $\mathrm{C} 2 \mathrm{C} 12$ myotubes. PTF improved insulin-stimulated glucose uptake in a dose- and time-dependent manner in $\mathrm{C} 2 \mathrm{C} 12$ myotubes, and prevented palmitate-induced IR. Furthermore, PTF enhanced the basal gene expression of Src and Akt2, elevated the protein expression of $\beta$-arrestin- 2 , Src and Akt, increased the phosphorylation of insulin receptor- $\beta$ at Tyr1150/1151 and Akt at Thr308/Ser473 in an insulin-dependent manner, but had no effects on the protein expression of PI3K-p85 or the activity of PI3K. Inhibition of Src but not PI3K restrained PTF-induced
\end{abstract}

Correspondence to: Dr Yi Liu or Dr Wen-Jian Wang, Institute of Chinese Integrative Medicine, Huashan Hospital, Fudan University, 12 Middle Wulumuqi Road, Shanghai 200040, P.R. China

E-mail: quyuan9657@163.com

E-mail:wj6518@163.com

Key words: Pollen Typhae total flavone, insulin resistance, $\beta$-arrestin-2, C2C12 myotubes, traditional Chinese medicine phosphorylation of Akt and glucose uptake. Our findings indicate that PTF improves insulin-induced glucose uptake via the $\beta$-arrestin-2-mediated signaling in $\mathrm{C} 2 \mathrm{C} 12$ myotubes.

\section{Introduction}

As the largest insulin-sensitive tissue, skeletal muscle is considered the most important tissue for insulin-mediated glucose disposal, accounting for approximately $80 \%$ of insulin-stimulated glucose uptake (1). Defects in insulininduced glucose uptake in the tissue are strongly linked to insulin resistance (IR) (2), a hallmark of metabolic diseases including type 2 diabetes and the metabolic syndrome. The prevalence of these conditions continues to rise thus imposing an enormous healthcare burden worldwide $(3,4)$.

IR is simply the inability of insulin to stimulate insulin signaling. Under insulin stimulation, the activated insulin receptor (InsR) recruits and phosphorylates insulin receptor substrate proteins (IRS), causing activation of the phosphatidylinositol-3 kinase (PI3K) that phosphorylates phosphatidylinositol-4,5-bisphosphate $\left(\mathrm{PIP}_{2}\right)$ to generate phosphatidylinositol-3,4,5-triphosphate $\left(\mathrm{PIP}_{3}\right)$ which recruits phosphoinositide-dependent kinase 1/2 (PDK1/2) and the three known isoforms of Akt/protein kinase $\mathrm{B}$ (PKB), and then PDK1 and PDK2 phosphorylate Akt/PKB on Thr308/ Ser473 respectively. Activated Akt/PKB regulates downstream targets such as glucose transporter-4 (Glut4), glycogen synthase kinase 3 (GSK3), forkhead box O1 (Foxo1), hormone sensitive lipase (HSL), and mTOR, thus being responsible for most of the metabolic actions of insulin to maintain glucose, fat and protein homeostasis, including glucose uptake, glucose synthesis, and gluconeogenesis (5-9). It is well known that the inactivation of the PI3K pathway leads to IR, showing a decrease in insulin-induced glucose uptake and disposal $(10,11)$. Recently, a novel insulin signaling dependent on $\beta$-arrestin- 2 has been discovered (12). Upon stimulation by insulin, $\beta$-arrestin-2 scaffolds Src and Akt to InsR, causing the 
formation of a new $\beta$-arrestin-2 signal complex, which allows Src to phosphorylate Akt, thus enhancing the phosphorylation of Akt at Thr308/Ser473, and subsequently regulating insulinmediated phosphorylation of GSK3 and Foxo1, promoting insulin-stimulated translocation of Glut4 from intracellular organelles (endosomes) to the cell surface within insulinresponsive tissues, where Glut4 binds glucose and is in charge of glucose uptake $(12,13)$. Loss or dysfunction of $\beta$-arrestin-2 leads to deficiency of this complex and disturbance of the signaling, resulting in IR and progression of type 2 diabetes. On the contrary, overexpression of $\beta$-arrestin- 2 promotes the formation of the complex, and improves insulin sensitivity in insulin resistance model animals (12,14-16). $\beta$-arrestin- 2 and the $\beta$-arrestin-2-mediated signaling display a potential role in preventing IR. Therefore, a strategy for enhancing glucose uptake is to preserve or strengthen the $\beta$-arrestin-2-mediated signaling.

Pollen Typhae is the pollen of several species of the genus Typha (Typhaceae) including T. angustifolia L., T. orientalis Presl., T. davidiana Hand.-Mazz. and T. minima Funk. It has been widely used to treat trauma, haematemesis, metrorrhagia, dysmenorrhea, hematuria and stranguria in Chinese medical clinical practice. Increasing evidence also indicates that Pollen Typhae performs a series of pharmacological functions. For example, Pollen Typhae improves the microcirculation, ameliorates dyslipidemia, and prevents and controls coronary heart diseases and myocardial infarction $(17,18)$. Moreover, it shows cytotoxicity against tumor cells (19), and regulates immune activity (20). Studies have proven that the main constituents of Pollen Typhae contain flavones, linoleic acid, and other unsaturated fatty acids $(21,22)$. Pollen Typhae total flavone (PTF), the extract of Pollen Typhae, possesses anti-inflammatory and anticoagulant activities $(23,24)$. In clinical research and animal studies, the Chinese herbal medicine 'Yiqi Sanju Formula' chiefly consisting of Pollen Typhae and several other Chinese herbs has been used to treat type 2 diabetes, central obesity, and non-alcoholic fatty liver disease, characterized by IR, showing anti-IR activity (25-27). We have also reported that PTF ameliorated high-glucose- and high-insulin-induced impairment of glucose uptake in 3T3-L1 adipocytes (28), suggesting the ability of PTF to improve IR, but the potential molecular mechanisms remain unclear.

The aim of this study was to investigate the effects of PTF on glucose uptake, and to explore the underlying molecular mechanisms in $\mathrm{C} 2 \mathrm{C} 12$ myotubes.

\section{Materials and methods}

Reagents. Dulbecco's modified Eagle's medium (DMEM), fetal calf serum (FCS), and horse serum were purchased from Gibco (Grand Island, NY). PP2, wortmannin, insulin solution, bovine serum albumin (BSA), palmitic acid, 2,3-bis(2-methoxy-4-nitro-5-sulfophenyl)-5-[(phenylamino) carbonyl]-2H-tetrazolium hydroxide (XTT), and cytochalasin B were obtained from Sigma (St. Louis, MO), fatty acid-free BSA was from Roche (Mannheim, Germany). Culture plates were from Corning (New York, NY). 2-Deoxy-D-[2,6- $\left.{ }^{3} \mathrm{H}\right]$ glucose (2-DOG) was obtained from Amersham (Buckinghamshire, UK). Antibodies directed against Akt (total), Akt (phosphorylated Thr308), Akt (phosphorylated Ser473), and PI3K-p85 were

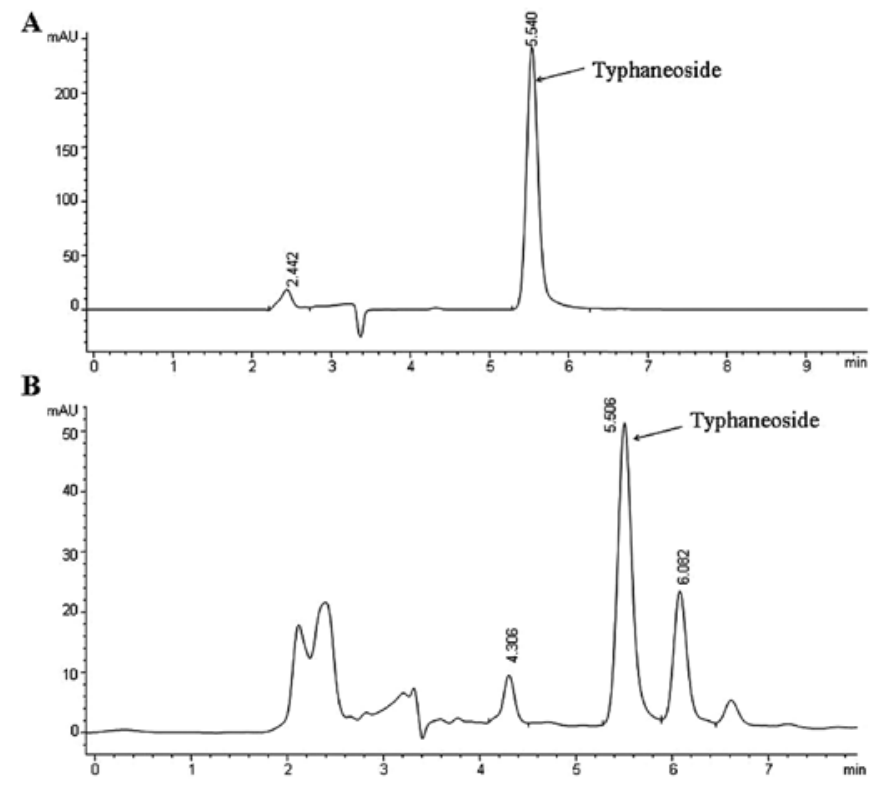

Figure 1. Chemical profiles of PTF by HPLC. (A) Typhaneoside. (B) Sample.

from Cell Signaling Technology (Danvers, MA). Secondary HRP-conjugated antibodies and antibodies to InsR- $\beta$ (phosphorylated Tyr1150/1151), Src, and $\beta$-arrestin-2 were purchased from Santa Cruz Biotechnology, Inc. (Santa Cruz, CA). The PI3K ELISA kit was from Echelon Biosciences and BCA protein assay kit was from Pierce (Rockford, IL). TRIzol reagents were purchased from Invitrogen Life Technologies (Carlsbad, CA).

Preparation of PTF. The pollen of T. angustifolia L. was collected in Anguo, Hebei, China, in June 2004, and authenticated by W.-J.W. based on microscopic and macroscopic characteristics. The fresh pollen of T. angustifolia L. was dried at $37^{\circ} \mathrm{C}$ with protection from light, and ground into powder. The extract of pollen of T. angustifolia L. was obtained as described with some modifications $(20,21)$. Briefly, the material (500 g) was extracted with 70\% ethanol three times under reflux for $1 \mathrm{~h}$. After filtration and concentration in rotavapour at $45^{\circ} \mathrm{C}$ until there was no flavor of ethanol, the solution was extracted with n-butyl alcohol three times. The combined solution was then concentrated under reduced pressure in rotavapor at $45^{\circ} \mathrm{C}$ to evaporate the solvent, and finally dried in high vacuum. The dried extract weighed $8.78 \mathrm{~g}$ (yield $1.76 \%$, w/w), which was determined to be PTF by HPLC according to the study by Yang et al (21), which contains Typhaneoside and undefined components (Fig. 1). The specimens of dried pollen of T. angustifolia L. and extract were deposited in the Institute of Chinese Integrative Medicine, Huashan Hospital, Fudan University, Shanghai, China.

Cell culture and differentiation. C2C12 myoblasts were obtained from the American Type Culture Collection (Manassas, VA). The cells were maintained in DMEM supplemented with $10 \%$ (vol/vol) FCS and antibiotics (penicillin $100 \mathrm{U} / \mathrm{ml}$, streptomycin $100 \mu \mathrm{g} / \mathrm{ml}$ ) for growth at $37^{\circ} \mathrm{C}$ under a humidified atmosphere containing $5 \% \mathrm{CO}_{2}$. For differentiation of myotubes, C2C12 myoblasts were transferred to DMEM containing $2 \%$ horse serum when the cells reached confluence. 


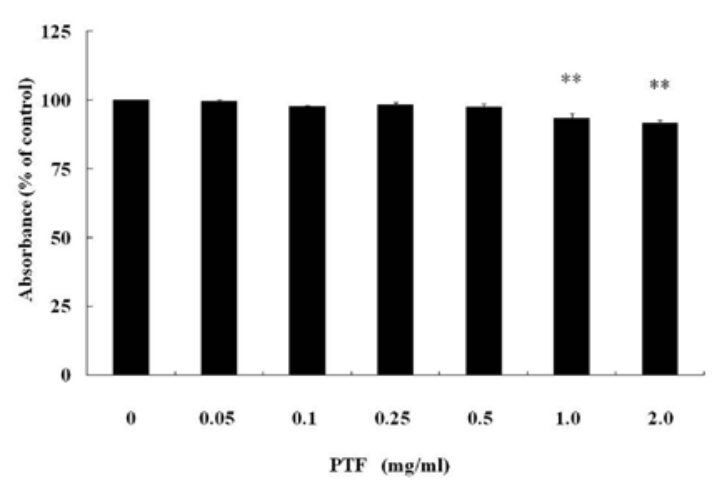

Figure 2. Cytotoxicity of PTF in $\mathrm{C} 2 \mathrm{C} 12$ myotubes. $\mathrm{C} 2 \mathrm{C} 12$ myotubes in 96-well culture plates were treated with PTF for $24 \mathrm{~h}$ after serum starvation in 1\% BSA-DMEM. Cytotoxicity was detected by the XTT assay. $\mathrm{n}=7$, ** $\mathrm{P}<0.01$ vs. control $(0 \mathrm{mg} / \mathrm{ml})$.

After an additional 4 days, the cells fused into myotubes, which were used in the subsequent experiments. The medium was changed every other day.

Cytotoxicity analysis. The cytotoxicity of PTF was determined by the XTT assay (29). C2C12 myoblasts were cultured in 96-well culture plates. After differentiation, the medium was replaced by serum-free DMEM supplemented with $1 \%$ BSA, and the cells were cultured for $12 \mathrm{~h}$. C2C12 myotubes in each well were then treated with $100 \mu 1$ serum-free $1 \%$ BSA-DMEM containing different concentrations of PTF $(0$, $0.05,0.1,0.25,0.5,1.0$ and $2.0 \mathrm{mg} / \mathrm{ml})$. After treatment for $24 \mathrm{~h}, 50 \mu \mathrm{l}$ of $0.1 \%$ XTT dissolved in serum-free DMEM was added directly into each well. After incubation for $4 \mathrm{~h}$ at $37^{\circ} \mathrm{C}$, the optical absorbance was read on a microplate reader (ELX 800; Bio-Tek Instruments, Winooski, VT) at $490 \mathrm{~nm}$.

Glucose uptake assay. Glucose uptake was determined by measuring the transport of 2-DOG into the cells as previously described with some modifications (30). C2C12 myoblasts were differentiated in 24-well culture plates. After 12-h serum deprivation and then PTF treatment for different times (8, 16 and $24 \mathrm{~h}$ ), the cells were washed three times with KrebsRinger phosphate buffer (KRPB) (10 mM HEPES, $131.2 \mathrm{mM}$ $\mathrm{NaCl}, 4.7 \mathrm{mM} \mathrm{KCl}, 1.2 \mathrm{mM} \mathrm{MgSO}{ }_{4}, 2.5 \mathrm{mM} \mathrm{CaCl}_{2}, 2.5 \mathrm{mM}$ $\mathrm{NaH}_{2} \mathrm{PO}_{4}, \mathrm{pH}$ 7.4), and then incubated in KRPB with or without $100 \mathrm{nM}$ insulin at $37^{\circ} \mathrm{C}$. After $20 \mathrm{~min}, 0.5 \mu \mathrm{Ci} / \mathrm{ml}$ 2-DOG was added to the cells. After $10 \mathrm{~min}$ incubation, the cells were washed three times with ice-cold PBS containing $10 \mathrm{mM}$ glucose to terminate the reaction. Finally, the cells were lysed with $0.1 \mathrm{~N} \mathrm{NaOH}$ for $2 \mathrm{~h}$, and the radioactivity taken up by the cells was measured by a scintillation counter (Beckman Instruments). Non-specific glucose uptake was determined in the presence of $20 \mu \mathrm{M}$ cytochalasin $\mathrm{B}$, and this was subtracted from the total uptake to get specific glucose uptake.

Western blotting and ELISA assay. After 12-h serum deprivation, $\mathrm{C} 2 \mathrm{C} 12$ myotubes in 6-well plates were treated with PTF for $16 \mathrm{~h}$, and then incubated with or without $100 \mathrm{nM}$ insulin for $30 \mathrm{~min}$. The cells were washed three times with ice-cold PBS, and then lysed in cell lysis buffer (RIPA, $50 \mathrm{mM}$ Tris- $\mathrm{HCl}$, $150 \mathrm{mM} \mathrm{NaCl}, 1 \mathrm{mM}$ EDTA, $1 \%$ NP-40, $1 \mathrm{mM}$ PMSF, $2 \mu \mathrm{g} /$ $\mathrm{ml}$ pepstatin, $10 \mu \mathrm{g} / \mathrm{ml}$ leupeptin, $\mathrm{pH}$ 7.4). The insoluble lysate material was removed by centrifugation $(12,000 \mathrm{rpm}$ for $30 \mathrm{~min}, 4^{\circ} \mathrm{C}$ ), and the protein concentrations of supernatants were determined using a BCA protein assay kit, which were utilized for western blotting and ELISA as previously described (31). The cell lysates were boiled for $5 \mathrm{~min}$, and then separated via SDS-PAGE. The protein was electrophoretically transferred to polyvinylidene difluoride membranes. The membranes were incubated with the first antibody for $1-2 \mathrm{~h}$ and then the secondary antibody for 1-2 $\mathrm{h}$. Immunoreactive bands were visualized by incubation with ECL Plus detection reagents (Amersham Biosciences). For the measurement of PI3K activity, lysates were measured by ELISA per the manufacturer's instructions. The detection limits were 12.5 to $200 \mathrm{pmol}$ in $100 \mu 1$ detection volume.

Quantification of $m R N A$ levels by real-time PCR. The mRNA levels of $\beta$-arrestin-2, Src, and Akt 2 were identified by realtime PCR after reverse transcription as previously described (32). After 12-h serum deprivation, $\mathrm{C} 2 \mathrm{C} 12$ myotubes in 6-well culture plates were treated with PTF for $16 \mathrm{~h}$, and then washed three times with ice-cold PBS. Total-RNA was extracted from the cells using TRIzol reagents, and then transcribed into cDNA with a superscript first-strand cDNA synthesis system. The relative gene abundance was quantified by real-time PCR, the reactions were performed in an ABI 7500 sequence detection system. The sequences of primers used were: $\beta$-arrestin- 2 , forward, 5'-TCC CTA GGG CGG CAA GCT GT-3' and reverse, 5'-ACT GGG GGC GAG TTG GTG TGA-3'; Src, forward, 5'-TCG GAC ACC GTC ACC TCC CC-3' and reverse, 5'-GAC AAT CTG CAG CCG CTC CCC-3'; Akt2, forward, 5'-AAA AAG TGG CTC TGG TGT GTG GAG C-3' and reverse, 5'-GAC TGT GGT CCA CTG CAG GCA-3'; GAPDH, forward, 5'-CCC CAG CAA GGA CAC TGA GCA AGA G-3' and reverse, 5'-GCC CCT CCT GTT ATT ATG GGG GTC-3'.

Statistical analysis. The data are presented as means \pm standard error (SE). Changes in 2-DOG uptake between baseline and insulin stimulation (known as 2-DOG uptake induced by insulin) are expressed as $\delta$. All data were analyzed with SPSS 16.0 for Windows. To identify significant differences between the two groups, comparisons were analyzed by the Student's t-test. When multiple comparisons were performed, the significance was analyzed by one-way analysis of variance (ANOVA). A value of $\mathrm{P}<0.05$ was regarded as statistically significant.

\section{Results}

Cytotoxicity of PTF in C2C12 myotubes. The cytotoxicity of PTF in $\mathrm{C} 2 \mathrm{C} 12$ myotubes was examined after PTF treatment for $24 \mathrm{~h}$ (Fig. 2). In C2C12 myotubes, PTF treatment decreased cell activity in a dose-dependent manner. PTF doses of 0.05 $0.5 \mathrm{mg} / \mathrm{ml}$, were not cytotoxic, but PTF was cytotoxic $(\mathrm{P}<0.01)$ at the concentration of $1.0 \mathrm{mg} / \mathrm{ml}$ or above compared with the control $(0 \mathrm{mg} / \mathrm{ml})$.

PTF ameliorates insulin-stimulated glucose uptake in a doseand time-dependent manner in C2C12 myotubes. Glucose uptake was investigated for PTF in $\mathrm{C} 2 \mathrm{C} 12$ myotubes with 2-DOG. In the absence of insulin, 2-DOG uptake was not promoted with PTF treatment for 8,16 or $24 \mathrm{~h}$ (Fig. 3A, C 

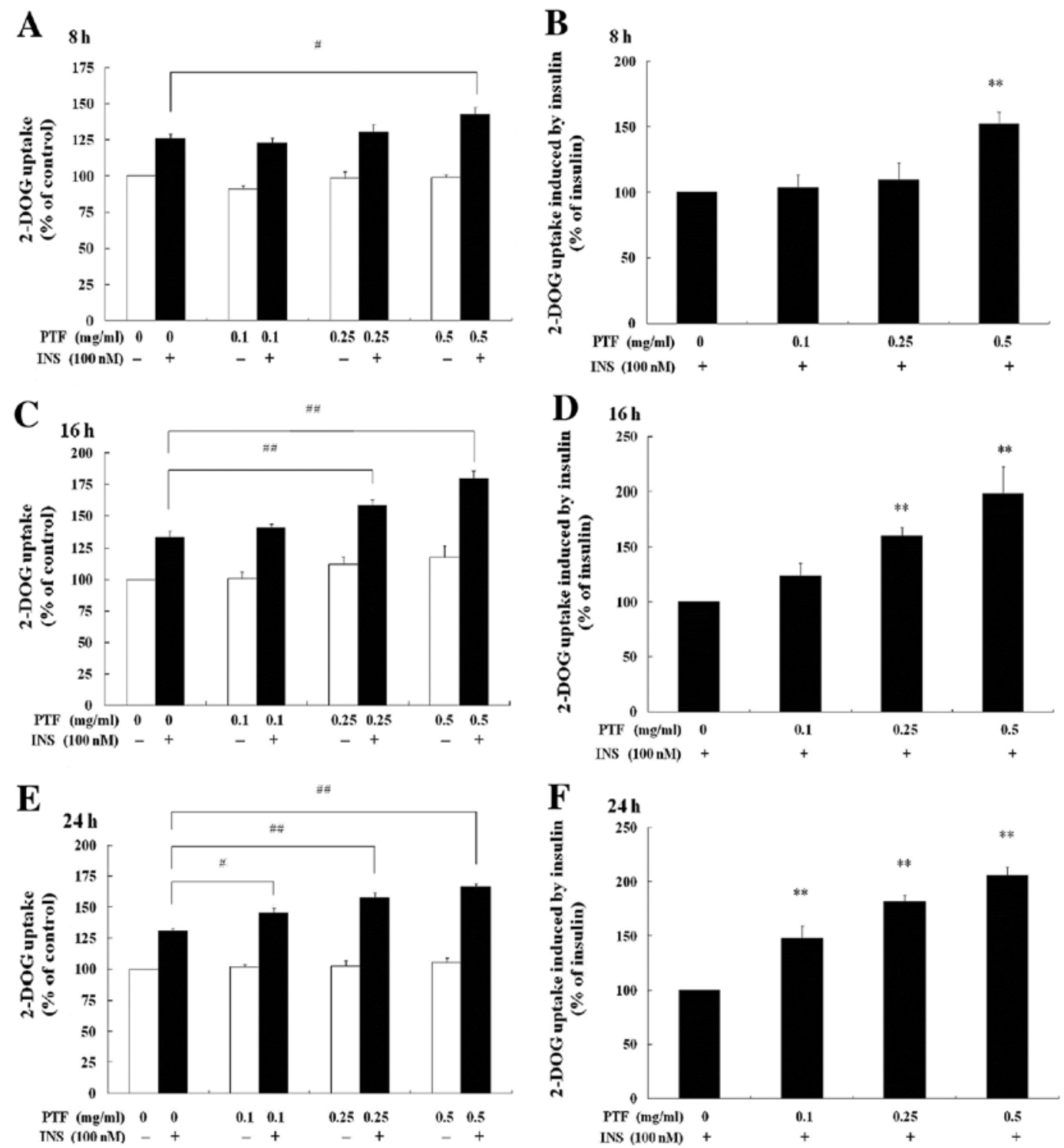

Figure 3. Effects of PTF on glucose uptake in $\mathrm{C} 2 \mathrm{C} 12$ myotubes. After serum starvation in 1\% BSA-DMEM and PTF pre-treatment for the indicated times, C2C12 myotubes in 24-well culture plates were treated with or without insulin (INS, $100 \mathrm{nM}$ ) for $20 \mathrm{~min}$ and glucose uptake was determined with 2-DOG. (A) 2-DOG uptake after 8 h. (B) 2-DOG uptake induced by insulin after 8 h. (C) 2-DOG uptake after $16 \mathrm{~h}$. (D) 2-DOG uptake induced by insulin after $16 \mathrm{~h}$. (E) 2-DOG uptake after 24 h. (F) 2-DOG uptake induced by insulin after 24 h. $\mathrm{n}=6,{ }^{\#} \mathrm{P}<0.05,{ }^{\# \prime} \mathrm{P}<0.01 ;{ }^{* *} \mathrm{P}<0.01$ vs. INS alone.

and $\mathrm{E})$ at all concentrations $(0.1,0.25$ or $0.5 \mathrm{mg} / \mathrm{ml})$ compared with the control $(0 \mathrm{mg} / \mathrm{ml} \mathrm{PTF})$. In the presence of insulin, compared with insulin alone, only $0.5 \mathrm{mg} / \mathrm{ml}$ PTF increased insulin-induced 2-DOG uptake by $52.26 \%(\mathrm{P}<0.01)$ after PTF pre-treatment for $8 \mathrm{~h}$ (Fig. 3B). After PTF pre-treatment for $16 \mathrm{~h}$ (Fig. 3D), both 0.25 and $0.5 \mathrm{mg} / \mathrm{ml}$ PTF dramatically improved insulin-induced 2-DOG uptake by $60.00 \%(\mathrm{P}<0.01)$ and $98.76 \%(\mathrm{P}<0.01)$ respectively. Additionally, after PTF pre-treatment for $24 \mathrm{~h}$ (Fig. 3F), PTF at all concentrations of $0.1,0.25$ and $0.5 \mathrm{mg} / \mathrm{ml}$ prominently enhanced insulin-induced 2-DOG uptake by $47.60 \%(\mathrm{P}<0.01), 81.46 \%(\mathrm{P}<0.01)$ and $105.82 \%(\mathrm{P}<0.01)$, respectively. These results indicate that PTF improves glucose uptake in an insulin-dependent manner in $\mathrm{C} 2 \mathrm{C} 12$ myotubes, suggesting the potential ability of PTF to ameliorate IR.

PTF prevents palmitate-induced IR in C2C12 myotubes. According to Reaven's initial studies (33), IR is defined as a decrease in insulin-mediated glucose uptake. In our previous study (28), PTF was established to improve high-glucose- and high insulin-induced IR in 3T3-L1 adipocytes. In order to determine whether PTF ameliorate IR in C2C12 myotubes, palmitate (PA) was used to induce IR according to the study by Senn (31). PA $(0.5 \mathrm{mM})$ pre-treatment for $16 \mathrm{~h}$ resulted in a reduction in insulin-induced glucose uptake by $63.69 \%$ $(\mathrm{P}<0.01)$ in $\mathrm{C} 2 \mathrm{C} 12$ myotubes compared with insulin alone (Fig. 4B). After both PTF and PA pre-treatment for $16 \mathrm{~h}$, PTF $(0.5 \mathrm{mg} / \mathrm{ml})$ notably increased insulin-mediated glucose uptake $(\mathrm{P}<0.01)$ compared with $\mathrm{PA}+$ insulin (Fig. 4D), which was similar to insulin alone $(\mathrm{P}>0.05)$.

PTF has no effects on the protein expression of p85 or the activity of PI3K in C2C12 myotubes. To gain insight into the molecular mechanisms, we observed the effects of PTF on insulin signaling. PI3K, which consists of a regulatory $(\mathrm{p} 85)$ and a catalytic subunit (p110), and plays a key role in the PI3K 
A
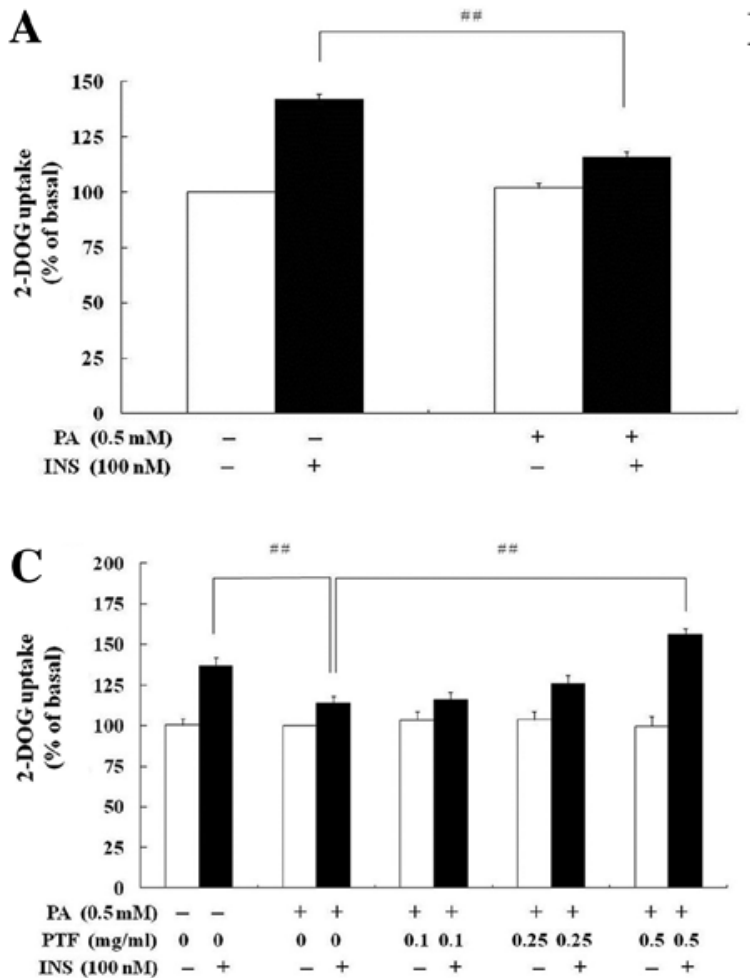

B

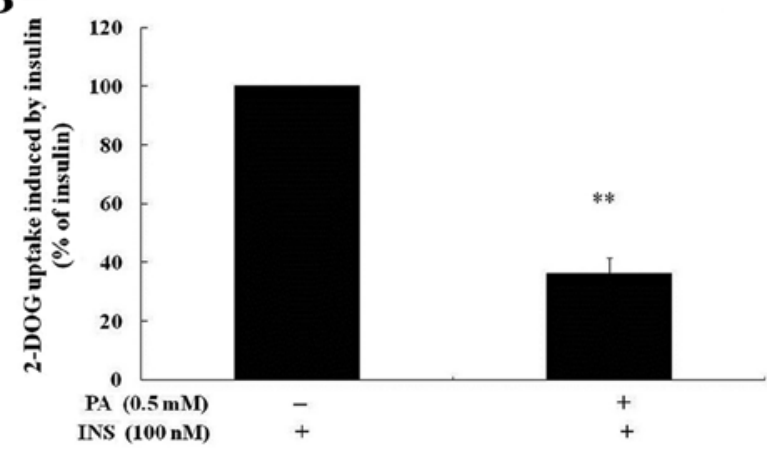

D

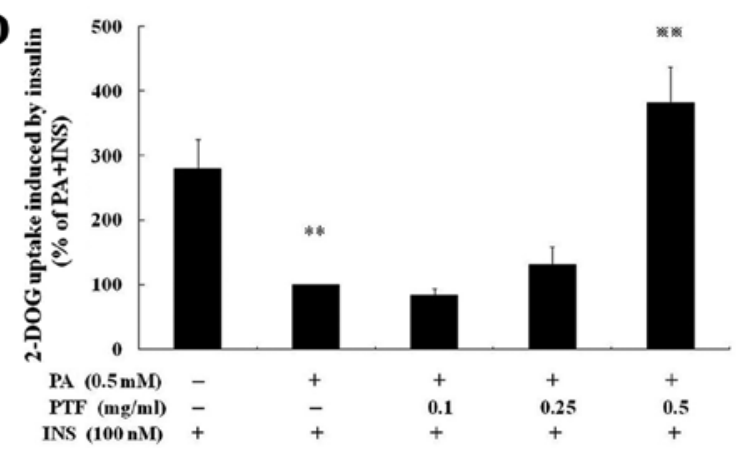

Figure 4. Effects of PTF on palmitate-induced insulin resistance in C2C12 myotubes. After serum starvation in 1\% BSA-DMEM, C2C12 myotubes in 24-well culture plates were treated with palmitate (PA) and/or PTF for $16 \mathrm{~h}$, and then incubated with or without insulin for 20 min. Glucose uptake was determined with 2-DOG. (A) Effects of PA on 2-DOG uptake. (B) Effects of PA on insulin-induced 2-DOG uptake. (C) Effect of PTF on PA-induced 2-DOG uptake. (D) Effect of PTF on insulin + PA-induced 2-DOG uptake. $\mathrm{n}=6,{ }^{* \#} \mathrm{P}<0.01 ;{ }^{* *} \mathrm{P}<0.01$ vs. INS alone; ${ }^{* *} \mathrm{P}<0.01$ vs. PA + INS.
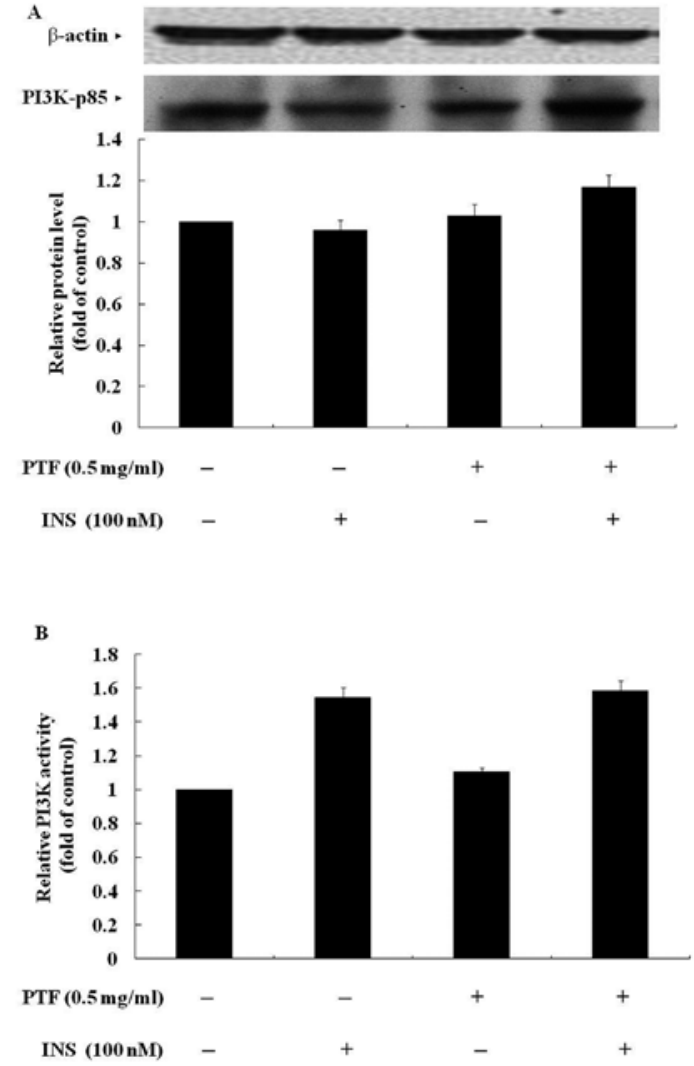

Figure 5. Effects of PTF on the protein expression of p85 and the activity of $\mathrm{PI} 3 \mathrm{~K}$ in $\mathrm{C} 2 \mathrm{C} 12$ myotubes. Serum-starved $\mathrm{C} 2 \mathrm{C} 12$ myotubes were treated with or without PTF for $16 \mathrm{~h}$ and then with or without insulin for $30 \mathrm{~min}$. Cells were lysed, and (A) the protein expression of $\mathrm{p} 85$ and (B) the activity of PI3K were determined by western blotting and ELISA, respectively. pathway, was firstly investigated. Western blotting showed that $\mathrm{C} 2 \mathrm{C} 12$ myotubes were pre-treated with PTF $(0.5 \mathrm{mg} / \mathrm{ml})$ for $16 \mathrm{~h}$, the protein expression of $\mathrm{p} 85$ was not obviously changed whether there was insulin to stimulate the cells for $30 \mathrm{~min}$ or not (Fig. 5A). The ELISA assay revealed that the activity of PI3K was not induced with PTF treatment for $16 \mathrm{~h}$ in the absence of insulin. In the presence of insulin, insulin obviously increased the activity of PI3K, and PTF pre-treatment for $16 \mathrm{~h}$ did not further enhance the activity of PI3K (Fig. 5B). These data indicate that PTF exhibits few effects on the protein expression of p85 and the activity of PI3K, suggesting that PTF improves insulin-induced glucose uptake independent of PI3K.

PTF improves the phosphorylation of InsR- $\beta$ in an insulin-dependent manner in C2C12 myotubes. Tyrosine autophosphorylation of InsR, comprised of two extracellular $\alpha$ subunits and two intracellular $\beta$ subunits, is one of the earliest cellular responses to insulin stimulation. Autophosphorylation begins with the phosphorylation of $\beta$ subunits at Tyr1146 and either Tyr1150/1151, which are required for full InsR activation (34). In the absence of insulin, PTF treatment for $16 \mathrm{~h}$ did not increase the phosphorylation of InsR- $\beta$ at Tyr1150/1151 compared with the control. In the presence of insulin, however, insulin increased InsR- $\beta$ phosphorylation, and PTF pre-treatment for $16 \mathrm{~h}$ further enhanced insulin-induced phosphorylation by $28.93 \%(\mathrm{P}<0.05)$ compared with insulin alone (Fig. 6A and B). These results suggest that PTF increases the phosphorylation of InsR- $\beta$ in an insulin-dependent manner, and that PTF improves insulin-induced glucose uptake through another pathway independent of PI3K. 

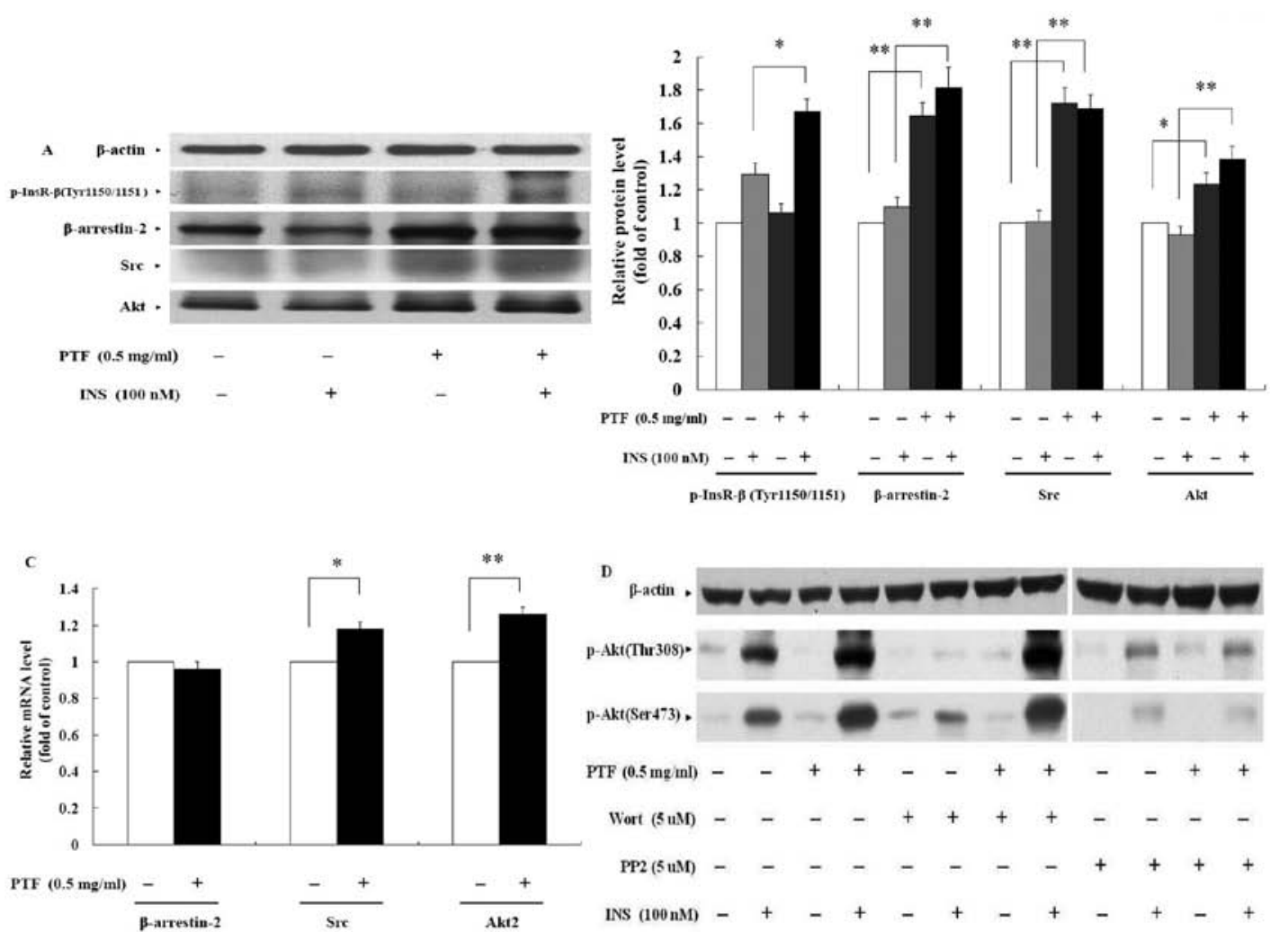

,
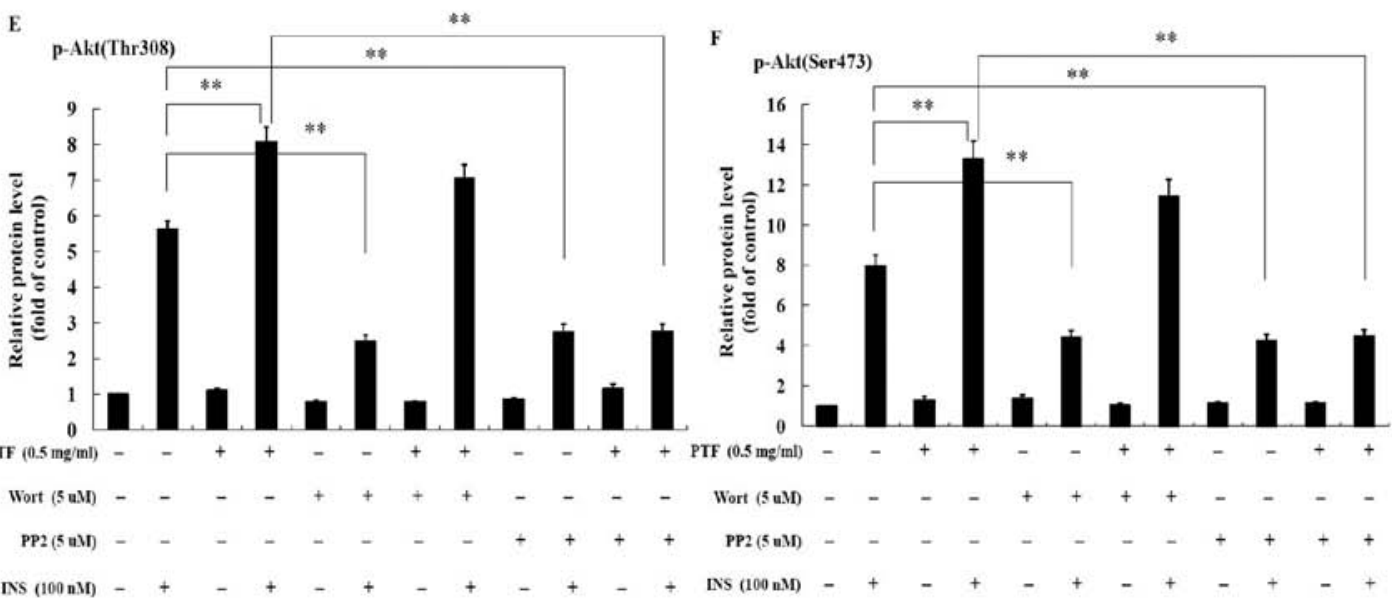

Figure 6. Effects of PTF on the $\beta$-arrestin-2-mediated signaling in $\mathrm{C} 2 \mathrm{C} 12$ myotubes. C2C12 myotubes were pre-treated with or without PTF, wortmannin (Wort) or PP2 for $16 \mathrm{~h}$ after serum starvation in 1\% BSA-DMEM, and the cells were then stimulated with or without insulin for 30 min. The cells were either lysed or used for total-RNA extraction. Whole cell lysate protein was examined by western blotting, and gene expression was assayed by real-time PCR. (A) Western blotting of p-InsR (Tyr1150/1151), $\beta$-arrestin-2, Src and Akt. (B) Densitometric analysis of active InsR (p-Tyr1150/1151), $\beta$-arrestin-2, Src and Akt. (C) Relative mRNA levels of $\beta$-arrestin-2, Src and Akt2. (D) Western blotting of p-Akt. (E) Densitometric analysis of active Akt (p-Thr308). (F) Densitometric analysis of active Akt (p-Ser473). ${ }^{*} \mathrm{P}<0.05,{ }^{* *} \mathrm{P}<0.01$.

PTF enhances the protein expression of $\beta$-arrestin- 2 with no effect on the basal gene expression in C2C12 myotubes. In addition to the PI3K pathway, the second pathway downstream of InsR is required for full Akt activation $(12,15,16)$. In the $\beta$-arrestin-2-mediated signaling, $\beta$-arrestin- 2 scaffolds Akt and Src to InsR upon insulin stimulation, causing the formation of the $\beta$-arrestin- 2 signal complex, thereby regulating insulin-stimulated glucose disposal including glucose uptake. In view of the results, it was likely that PTF enhanced insulinmediated glucose uptake via this signaling. Compared with the control and insulin alone, PTF pre-treatment of $\mathrm{C} 2 \mathrm{C} 12$ myotubes for $16 \mathrm{~h}$ prominently increased the protein expres- sion of $\beta$-arrestin-2 by $64.60 \%(\mathrm{P}<0.01)$ and $65.51 \%(\mathrm{P}<0.01)$ respectively (Fig. 6A and $\mathrm{B}$ ). However, real-time PCR assay revealed that mRNA levels of $\beta$-arrestin- 2 were not enhanced with PTF treatment for $16 \mathrm{~h}$ (Fig. 6C).

PTF increases the protein and the basal gene expression of Src in C2C12 myotubes. In the $\beta$-arrestin- 2 complex $(12,15,16)$, Src phosphorylates Akt on Tyr315/326 which is required for the subsequent phosphorylation of Akt at Thr308/Ser473. In this study, the protein expression of Src in $\mathrm{C} 2 \mathrm{C} 12$ myotubes was elevated by $72.23 \%(\mathrm{P}<0.01)$ and $67.48 \%(\mathrm{P}<0.01)$ with PTF pre-treatment for $16 \mathrm{~h}$ compared with the control and 
A
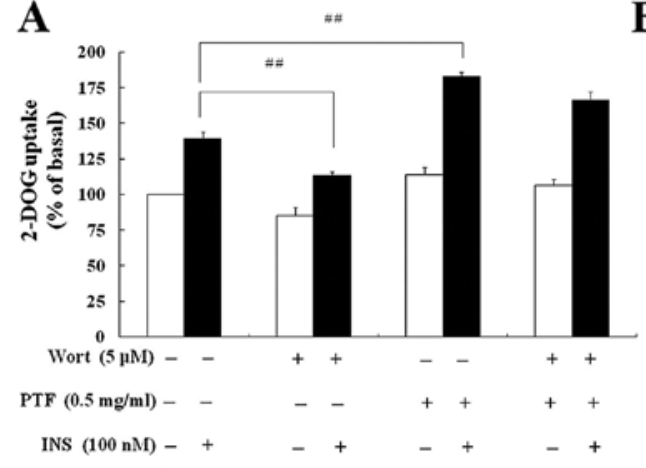

C

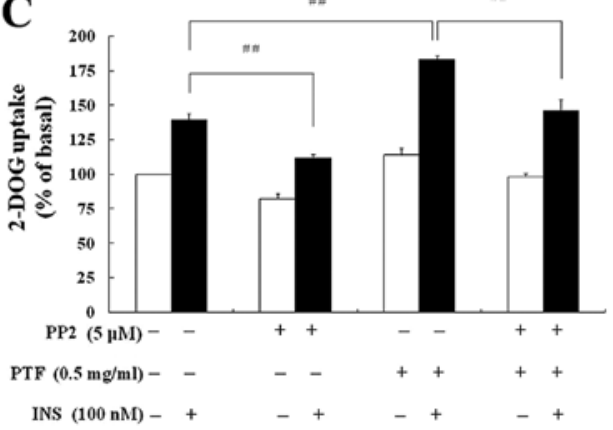

B

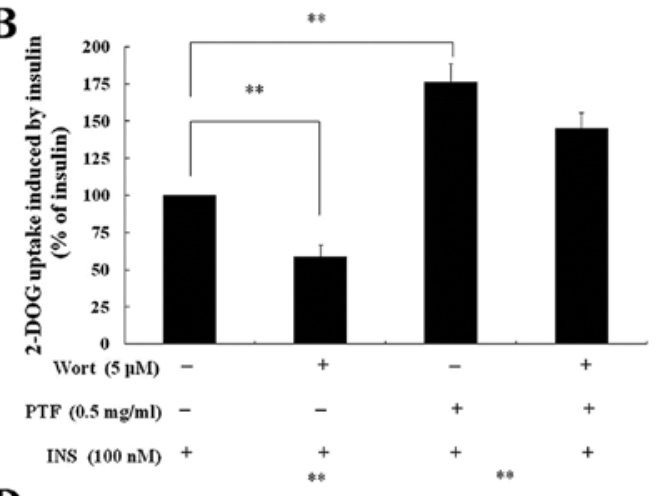

$\mathbf{D}$

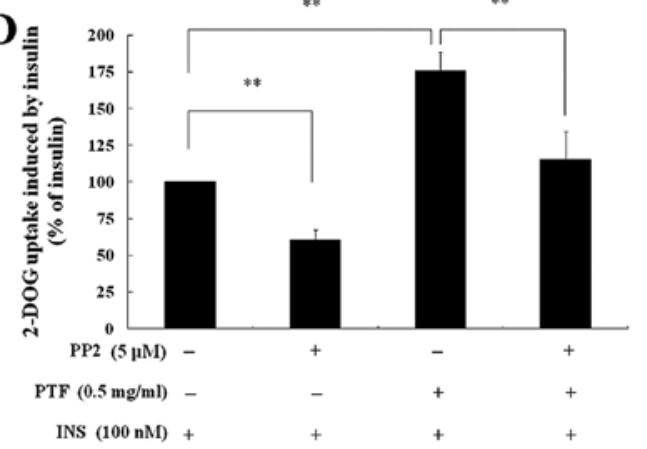

Figure 7. Improvement of insulin-induced glucose uptake by PTF is inhibited by PP2 but not wortmannin. Serum-starved C2C12 myotubes in 24-well culture plates were treated with wortmannin, PP2 and PTF for $16 \mathrm{~h}$, and then stimulated with or without insulin for 20 min. Glucose uptake was determined with 2-DOG. (A) Effects of wortmannin on 2-DOG uptake. (B) Effects of wortmannin on PTF + insulin-induced 2-DOG uptake. (C) Effects of PP2 on 2-DOG uptake. (D) Effects of PP2 on PTF + insulin-induced 2-DOG uptake. $n=6,{ }^{* *} \mathrm{P}<0.01,{ }^{\# \#} \mathrm{P}<0.01$.

insulin alone, respectively (Fig. 6A and B). Moreover, PTF increased mRNA expression of Src compared with the control $(\mathrm{P}<0.05)$ (Fig. 6C).

PTF elevates the protein and the basal gene expression of Akt, and improves the phosphorylation of Akt in an insulindependent manner in C2C12 myotubes. Akt is the downstream target of Src in the $\beta$-arrestin- 2 complex, and has three isoforms in mammals, each encoded by a different gene (Akt1-3), where Akt 2 is closely related with the insulin-induced glucose uptake (35,36). Phosphorylation of Akt at Thr308/Ser473 stands for its full activation (6-8). In $\mathrm{C} 2 \mathrm{C} 12$ myotubes, compared with the control and insulin alone, PTF pre-treatment for $16 \mathrm{~h}$ markedly increased the protein expression of Akt by $23.61 \%(\mathrm{P}<0.05)$ and $48.83 \%$ ( $\mathrm{P}<0.01$ ), respectively (Fig. 6A and B). Similarly, mRNA levels of Akt 2 with PTF treatment for $16 \mathrm{~h}$ were enhanced $(\mathrm{P}<0.01)$ compared with the control (Fig. 6C).

In the absence of insulin, PTF did not elevate the phosphorylation of Akt at Thr308 or Ser473. The phosphorylation was significantly increased with insulin stimulation for $30 \mathrm{~min}$, and PTF further enhanced the insulin-induced phosphorylation at Thr308 by $44.02 \%(\mathrm{P}<0.01)$ (Fig. 6D and E) and Ser473 by $66.10 \%(\mathrm{P}<0.01)$ (Fig. 6D and F) after PTF pre-treatment for $16 \mathrm{~h}$.

Wortmannin, an inhibitor of PI3K, used to pre-treat C2C12 myotubes for $16 \mathrm{~h}$, remarkably inhibited insulininduced phosphorylation of Akt at Thr308 by 55.95\% ( $<<0.01)$ (Fig. 6D and E) and Ser473 by $44.56 \%(\mathrm{P}<0.01)$ (Fig. 6D and F) compared with insulin alone, but failed to inhibit PTF-induced phosphorylation ( $\mathrm{P}>0.05$ ) (Fig. 6D, E and F).

Similarly, PP2, an inhibitor of Src, significantly reduced insulin-induced phosphorylation of Akt at Thr308 by $51.18 \%$
$(\mathrm{P}<0.01)$ (Fig. 6D and E) and Ser473 by $46.83 \%(\mathrm{P}<0.01)$ (Fig. 6D and F) compared with insulin alone. Furthermore, PP2 also reduced PTF-induced phosphorylation at Thr308 by $65.74 \%(\mathrm{P}<0.01)$ (Fig. 6D and $\mathrm{E}$ ) and Ser473 by $66.06 \%$ $(\mathrm{P}<0.01)$ (Fig. 6D and F) compared with $\mathrm{PTF}+$ insulin.

Together, PTF increased the protein and the basal gene expression of Akt, and improved insulin-induced phosphorylation of Akt, which was inhibited by PP2 but not wortmannin. The data support the idea that PTF improves insulin-induced glucose uptake through the $\beta$-arrestin-2-mediated signaling in C2C12 myotubes.

Effects of wortmannin and PP2 on PTF-induced glucose uptake in C2C12 myotubes. Compared with insulin alone, wortmannin pre-treatment for $16 \mathrm{~h}$ resulted in a decrease in insulin-mediated 2-DOG uptake by $42.81 \%$ (P<0.01) (Fig. 7B), and $\mathrm{PP} 2$ by $38.33 \%(\mathrm{P}<0.01)$ (Fig. 7D). Compared with $\mathrm{PTF}+$ insulin, wortmannin + PTF + insulin only inhibited insulin-induced 2-DOG uptake by $15.79 \%$ (P>0.05) (Fig. 7B), but PP2 by $35.29 \%(\mathrm{P}<0.01)$ (Fig. 7D).

\section{Discussion}

Chinese herbs have been used to treat diabetes for thousands of years in Chinese clinical practice, and have become popular complementary and alternative medicine in the treatment of metabolic diseases by improving IR $(37,38)$. It is worthwhile to screen insulin sensitizing reagents from Chinese herbs, and to elucidate their molecular mechanisms. In this study, we found that PTF increased insulin-stimulated glucose uptake in a dose-dependent manner, and prevented PA-induced IR in $\mathrm{C} 2 \mathrm{C} 12$ myotubes, which conform to our previous report 
(28). Insulin signaling mainly refers to two pathways: the Ras-mitogen-activated protein kinase (MAPK) pathway, and the PI3K signaling. The former regulates expression of some genes, and controls growth and differentiation of cells $(5,6,8)$. The latter mediates most of the metabolic actions of insulin including insulin-induced glucose uptake. It is agreed that PA results in IR by restraining the PI3K pathway $(39,40)$, and that enhancing the activity of the PI3K pathway is the key strategy for improving glucose uptake and IR. In order to determine whether PTF has some relationship with the PI3K pathway in improving insulininduced glucose uptake, PI3K was hereby assayed, which consists of a regulatory (p85) and a catalytic subunit (p110) and plays a key role in the PI3K pathway. In the basal state, $\mathrm{p} 85$ binds to p110, thus inhibiting the activity of p110. Upon insulin stimulation, p85 associates with IRS and sets p110 free. In turn p110 catalyzes the production of $\mathrm{PIP}_{3}$, which recruits PDK1/2 and Akt $(8,41)$. In this study, PTF had no effects on the protein expression of $\mathrm{p} 85$ or the activity of PI3K. Interestingly, PTF prompted insulin-induced tyrosine phosphorylation of InsR- $\beta$ at Tyr1150/1151, the feature of InsR standing for the earliest activation, which is required for full kinase activation of InsR in triggering insulin signaling. The results indicate that PTF increases insulin-induced glucose uptake dependent on InsR but not PI3K, suggesting that PTF improves insulin-stimulated glucose uptake through another pathway.

During 2009, Luan et al (12) found another novel insulin signaling involving $\beta$-arrestin- $2, \mathrm{Src}$, InsR, and Akt, which provide new insight into the molecular pathogenesis of IR, and implicate a new strategy for screening insulin-sensitizing reagents to improve IR (42). Interestingly, PTF significantly enhanced the protein expression of $\beta$-arrestin- 2 in $\mathrm{C} 2 \mathrm{C} 12$ myotubes. It is generally accepted that $\beta$-arrestin- 2 is an important adaptor in modulating the strength and duration of cellular signaling by scaffolding and interacting with a lot of cytoplasmic proteins including InsR, Src and Akt $(15,16,43)$. Additionally, allowing for the improvement in the phosphorylation of InsR- $\beta$ by PTF, we inferred that PTF had some relationship with the $\beta$-arrestin-2-mediated signaling. Western blotting and real-time PCR assay revealed that PTF not only increased the protein expression of Src and Akt, but also prompted the gene expression of Src and Akt. According to the novel signaling, $\beta$-arrestin- 2 scaffolds Src and Akt to InsR upon insulin stimulation, causing the formation of the $\beta$-arrestin- 2 signal complex. Following autophosphorylation of InsR- $\beta$, Src phosphorylates Akt on Tyr315/326, which enhances the phosphorylation of Akt at Thr308 by PDK1 and at Ser 473 by PDK2 $(5,6,8)$. To our surprise, PTF increased the phosphorylation of Akt at Thr308 and Ser473.

In order to further confirm the results, PP2, the inhibitor of Src, was used to inhibit the activity of the $\beta$-arrestin-2-mediated signaling. The results exhibited that PP2 not only inhibited the insulin-induced phosphorylation of Akt, but also depressed the PTF-induced phosphorylation of Akt. Together, PTF had beneficial effects on the $\beta$-arrestin-2-mediated signaling. Since, PTF had no effects on PI3K, wortmannin, the inhibitor of PI3K, was used to inhibit the activity of the PI3K pathway. The results showed that wortmannin inhibited insulin-induced phosphorylation of Akt, but did not depress PTF-induced phosphorylation. The present study does not prove that the PI3K pathway is not required for the PTF-induced increase in insulin-mediated phosphorylation of Akt, because the phosphorylation of Akt at Thr308 and Ser473 is dependent on PI3K, and Src only affects the phosphorylation at Thr308 and Ser473 via phosphorylating Akt on Tyr315/326. PTF had beneficial effects on the $\beta$-arrestin-2-mediated signaling, thus to some extent compensating for the loss of the phosphorylation of Akt by wortmannin. On the other hand, PTF contains a number of constituents including typhaneoside, isorhamnetin, isorhamnetin-3-O-neohesperidoside, kaempferol, quercetin and so on $(21,44)$. It has been reported that isorhamnetin increases Akt activity in PC12 cells (45), kaempferol regulates lipopolysaccharide-induced phosphorylation of Akt in BV2 microglial cells (46), and quercetin protects oligodendrocyte precursor cells from oxygen/glucose deprivation injury in vitro via upregulating phosphorylation of Akt (47). It is expected that a certain ingredient or a specific constituent directly represses wortmannin, thus relieving the inhibition of wortmannin on the phosphorylation of Akt at Thr308/Ser473, which needs further studying. Activated Akt promotes insulinstimulated translocation of Glut4 from intracellular organelles (endosomes) to cell surface within insulin-responsive tissues including muscle and fat, where Glut 4 binds glucose and is in charge of glucose uptake (13). After transport of glucose into the skeletal muscle cells, glucose is mainly oxidized for energy, and used for glycogen synthesis. Skeletal muscle is not the site of gluconeogenesis due to a lack of gluconeogenesis enzyme. Consistent with our results involving Akt, glucose uptake induced by PTF was blocked by PP2 but not wortmannin, which further proved the beneficial effects of PTF on the $\beta$-arrestin-2-mediated signaling.

Furthermore, western blotting and real-time PCR analysis showed that PTF enhanced the protein expression of $\beta$-arrestin- 2 , but did not increase the gene expression. The ubiquitin system-induced ubiquitination and degradation of protein is an essential cellular mechanism. As previously reported (48-50), $\beta$-arrestin-2 is also an important regulator in the ubiquitin system-mediated ubiquitination of target proteins. $\beta$-arrestin- 2 not only scaffolds and recruits ubiquitin ligase substrates, such as GPCRs, to the ubiquitin ligase Mdm2, thereby augmenting E3-mediated ubiquitination of target proteins and blocking relevant cellular signaling, but also interacts with Mdm2, causing $\beta$-arrestin- 2 itself degradation by Mdm2 but competitively inhibiting ubiquitination of target proteins. Therefore, we propose that PTF may inhibit ubiquitination and degradation of $\beta$-arrestin- 2 to enhance its protein levels, which merits further investigation.

In conclusion, PTF increases insulin-induced glucose uptake through the $\beta$-arrestin-2-mediated signaling in $\mathrm{C} 2 \mathrm{C} 12$ myotubes. The findings suggest the potential uses of PTF, or compounds derived thereof, against type 2 diabetes and metabolic syndrome.

\section{Acknowledgements}

We thank Wei-Hua Chen and Jian Ying for providing technical assistance. This study was supported by the PhD Programs Foundation of the Ministry of Education of China (no. 20090071120047), the Leading Academic Discipline Project of Shanghai Municipal Education Commission (no. J50307), and the State Administration of Traditional Chinese Medicine. 


\section{References}

1. Baron AD, Brechtel G, Wallace P and Edelman SV: Rates and tissue sites of non-insulin- and insulin-mediated glucose uptake in humans. Am J Physiol 255: E769-E774, 1988.

2. Frøsig C and Richter EA: Improved insulin sensitivity after exercise: focus on insulin signaling. Obesity (Silver Spring) 17 (Suppl 3): S15-S20, 2009.

3. Yang $\mathrm{W}, \mathrm{Lu} \mathrm{J}$, Weng J, et al: Prevalence of diabetes among men and women in China. N Engl J Med 362: 1090-1101, 2010.

4. Fernandes J and Lofgren IE: Prevalence of metabolic syndrome and individual criteria in college students. J Am Coll Health 59: 313-321, 2011.

5. Burgering $\mathrm{BM}$ and Coffer PJ: Protein kinase $\mathrm{B}$ (c-Akt) in phosphatidylinositol-3-OH kinase signal transduction. Nature 376: 599-602, 1995

6. Alessi DR, Andjelkovic M, Caudwell B, et al: Mechanism of activation of protein kinase B by insulin and IGF-1. EMBO J 15 6541-6551, 1996.

7. Sarbassov DD, Guertin DA, Ali SM and Sabatini DM: Phosphorylation and regulation of $\mathrm{Akt} / \mathrm{PKB}$ by the rictor-mTOR complex. Science 307: 1098-1101, 2005.

8. Taniguchi CM, Emanuelli B and Kahn CR: Critical nodes in signalling pathways: insights into insulin action. Nat Rev Mo Cell Biol 7: 85-96, 2006.

9. Jacinto E, Facchinetti V, Liu D, et al: SIN1/MIP1 maintains rictor-mTOR complex integrity and regulates Akt phosphorylation and substrate specificity. Cell 127: 125-137, 2006.

10. Kadowaki T: Insights into insulin resistance and type 2 diabetes from knockout mouse models. J Clin Invest 106: 459-465, 2000.

11. Cusi K, Maezono K, Osman A, et al: Insulin resistance differentially affects the PI3-kanase-and MAP kinase-mediated signaling in human muscle. J Clin Invest 105: 311-320, 2000.

12. Luan B, Zhao J, Wu H, et al: Deficiency of a $\beta$-arrestin-2 signal complex contributes to insulin resistance. Nature 457: 1146-1149, 2009.

13. Marette A, Richardson JM, Ramlal T, et al: Abundance, localization, and insulin-induced translocation of glucose transporters in red and white muscle. Am J Physiol 263: C443-C452, 1992.

14. Jiang $\mathrm{T}$ and Qiu Y: Interaction between Src and a C-terminal proline-rich motif of Akt is required for Akt activation. J Biol Chem 278: 15789-15793, 2003.

15. Beaulieu JM, Sotnikova TD, Marion S, et al: An Akt/ $\beta$-arrestin 2/PP2A signaling complex mediates dopaminergic neurotransmission and behavior. Cell 122: 261-273, 2005.

16. Lodeiro M, Theodorpoulou M, Pardo M, et al: c-Src regulates Akt signaling in response to ghrelin via beta-arrestin signalingindependent and -dependent mechanisms. PLoS One 4: e4686, 2009.

17. Gibbs A, Green C and Doctor VM: Isolation and anticoagulant properties of polysaccharides of Typha augustata and Daemonoropes species. Thromb Res 32: 97-108, 1983.

18. Zhao J, Zhang CY, Xu DM, et al: The antiatherogenic effects of components isolated from pollen typhae. Thromb Res 57: 957-966, 1990

19. Chung S, Park $\mathrm{S}$ and Yang $\mathrm{CH}$ : Unsaturated fatty acids bind Myc-Max transcription factor and inhibit Myc-Max-DNA complex formation. Cancer Lett 188: 153-162, 2002.

20. Qin F and Sun HX: Immunosuppressive activity of Pollen Typhae ethanol extract on the immune responses in mice. $\mathrm{J}$ Ethnopharmacol 102: 424-429, 2005.

21. Yang Y, Wang S and Zhang S: Determination of flavonoids in pollen typhae (Puhuang) by HPCE and HPLC. Zhongguo Zhong Yao Za Zhi 24: 682-684, 703, 1999 (In Chinese).

22. Ma HF, Liu B, Zhang GY, et al: GC-MS analysis of the fatty components of Pollen Typhae before and after being carbonized. Zhongguo Zhong Yao Za Zhi 31: 200-202, 2006 (In Chinese).

23. Lou SY, Liu Y, Chen WH, et al: Pollen Typhae total flavones inhibit expression of interleukin-6 in $\mathrm{C} 2 \mathrm{C} 12$ skeletal muscle cells cultured with palmitate. Zhong Xi Yi Jie He Xue Bao 6: 488-492, 2008 (In Chinese)

24. Ohkura N, Tamura K, Tanaka A, et al: Experimental study on the hemostatc activity of Pollen Typhae: a traditional folk medicine used by external and oral application. Blood Coagul Fibrinolysis 22: 631-636, 2011

25. Lou SY, Liu Y, Ma YY, et al: Effects of Yiqi Sanju Formula on non-alcoholic fatty liver disease: a randomized controlled trial. Zhong Xi Yi Jie He Xue Bao 6: 793-798, 2008 (In Chinese).
26. He CY, Wang WJ,Li B, et al: Clinical research of Yiqi Sanju Formula in treating central obese men at high risk of metabolic syndrome. Zhong Xi Yi Jie He Xue Bao 5: 263-267, 2007 (In Chinese).

27. Zhang Z, Xue HL, Liu Y and Wang WJ: Yi-Qi-Zeng-Min-Tang, a Chinese medicine, ameliorates insulin resistance in type 2 diabetic rats. World J Gastroenterol 17: 987-995, 2011.

28. He YM, Wang WJ, Chen WH, et al: Effects of Pollen Typhae total flavone on glucose and lipid metabolism in 3T3-L1 adipocytes. Zhong Xi Yi Jie He Xue Bao 4: 593-595, 2006 (In Chinese).

29. Koulaouzidou EA, Economides N, Beltes P, et al: In vitro evaluation of the cytotoxicity of ProRoot MTA and MTA Angelus. J Oral Sci 50: 397-402, 2008.

30. Jiang B, Yang Y, Jin H, et al: Astragaloside IV attenuates lipolysis and improves insulin resistance induced by TNFalpha in 3T3-L1 adipocytes. Phytother Res 22: 1434-1439, 2008.

31. Senn JJ: Toll-like receptor-2 is essential for the development of palmitate-induced insulin resistance in myotubes. J Biol Chem 281: 26865-26875, 2006.

32. Xu A, Wang H, Hoo RL, et al: Selective elevation of adiponectin production by the natural compounds derived from a medicinal herb alleviates insulin resistance and glucose intolerance in obese mice. Endocrinology 150: 625-633, 2009.

33. Reaven GM: Role of insulin resistance in human disease. Diabetes 37: 1595-1607, 1988

34. White MF, Shoelson SE, Keutmann H and Kahn CR: A cascade of tyrosine autophosphorylation in the beta-subunit activates the phosphotransferase of the insulin receptor. J Biol Chem 263: 2969-2980, 1988.

35. George S, Rochford JJ, Wolfrum C, et al: A family with severe insulin resistance and diabetes due to a mutation in AKT2. Science 304: 1325-1328, 2004.

36. Lau P, Fitzsimmons RL, Pearen MA, et al: Homozygous staggerer $(\mathrm{sg} / \mathrm{sg})$ mice display improved insulin sensitivity and enhanced glucose uptake in skeletal muscle. Diabetologia 54: 1169-1180, 2011.

37. Chao M, Zou D, Zhang Y, et al: Improving insulin resistance with traditional Chinese medicine in type 2 diabetic patients. Endocrine 36: 268-274, 2009

38. Xie W and Du L: Diabetes is an inflammatory disease: evidence from traditional Chinese medicines. Diabetes Obes Metab 13: 289-301, 2011.

39. Dresner A, Laurent D, Marcucci M, et al: Effects of free fatty acids on glucose transport and IRS-1-associated phosphatidylinositol 3-kinase activity. J Clin Invest 103: 253-259, 1999.

40. Belfort R, Mandarino L, Kashyap S, et al: Dose response effect of elevated plasma FFA on insulin signaling. Diabetes 54: 1640-1648, 2005.

41. Neri LM, Borgatti P, Capitani S and Martelli AM: The nuclear phosphoinositide 3-kinase/AKT pathway: a new second messenger system. Biochim Biophys Acta 1584: 73-80, 2002.

42. Feng X, Wang W, Liu J and Liu Y: $\beta$-Arrestins: multifunctional signaling adaptors in type 2 diabetes. Mol Biol Rep 38: 2517-2528, 2011.

43. Gurevich VV and Gurevich EV: The structural basis of arrestinmediated regulation of $\mathrm{G}$ protein coupled receptor. Pharmacol Ther 110: 465-502, 2006.

44. Liu B and Lu Y: HPLC determination of two flavonoids in pollen Typhae (puhuang) and its different processed products. Zhongguo Zhong Yao Za Zhi 23: 402-404, 447, 1983 (In Chinese).

45. Hwanq SL and Yen GC: Modulation of Akt, JNK, and p38 activation is involved in citrus flavonoid-mediated cytoprotection of PC1 2 cells challenged by hydrogen peroxide. J Agric Food Chem 57: 2576-2582, 2009.

46. Park SE, Sapkota K, Kim S, et al: Kaempferol acts through mitogen-activated protein kinases and protein kinase B/AKT to elicit protection in a model of neuroinflammation in BV2 microglial cells. Br J Pharmacol 164: 1008-1025, 2011

47. Wang XQ, Yao RQ, Liu X, et al: Quercetin protects oligodendrocyte precursor cells from oxygen/glucose deprivation injury in vitro via the activation of the PI3K/Akt signaling pathway. Brain Res Bull 86: 277-284, 2011.

48. Isao UI, Takeshi I, Jie H, et al: $\beta$-Arrestin-1 competitively inhibits insulin-induced ubiquitination and degradation of insulin receptor substrate 1. Mol Cell Biol 24: 8929-8937, 2004.

49. Li X, Baillie GS and Houslay MD: Mdm2 directs the ubiquitination of beta-arrestin-sequestered cAMP phosphodiesterase-4D5. J Biol Chem 284: 16170-16182, 2009.

50. Nogués L, Salcedo A, Mayor F Jr and Penela P: Multiple scaffolding functions of (beta)-arrestins in the degradation of $\mathrm{G}$ protein-coupled receptor kinase 2. J Biol Chem 286: 1165-1173, 2011. 